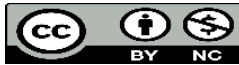

Licenciado sob uma licença Creative Commons

ISSN 2175-6058

https://doi.org/10.18759/rdgf.v19i2.1080

\title{
O FINANCIAMENTO DA EDUCAÇÃO BÁSICA NO BRASIL: ANÁLISE DOS PAPÉIS DOS ENTES FEDERADOS DA REPÚBLICA VELHA AOS DIAS ATUAIS
}

FINANCING OF BASIC EDUCATION IN BRAZIL: ANALYSIS OF FEDERATE ENTITIES FROM THE OLD REPUBLIC TO PRESENT $D A Y S$

\author{
Maria Stela Campos da Silva
}

Bianca Araujo de Oliveira Pereira

\section{RESUMO}

0 presente artigo aborda os papéis dos entes federados, da República Velha aos dias atuais, quanto ao financiamento da educação no Brasil, sustentando a hipótese de que, ao longo dos anos, a forma de financiamento apresentou melhorias quanto à definição dos recursos e competências dos entes, especialmente da União. É feito um exame das constituições e legislações ordinárias que tratam da matéria em cada espaço de tempo, para analisar tais mudanças, com base nas competências do Estado Federado. Ao final, é apontada a melhora da forma de destinação de recursos, com atenção à tendência de governos conservadores não priorizarem esta área em suas agendas, o que afeta sensivelmente o direito à uma educação adequada e seu financiamento.

Palavras-chave: Federalismo. Financiamento da educação. Entes federados. 


\section{Abstract}

The present article approaches federated entities' roles in Brazil, from the Old Republic to the present days, regarding the financing of education in Brazil. The supported hypothesis is that, over the years, the form of financing presented several improvements about the resources and competences of the federal entities, especially the Union (as it is called the Federal Government in Brazil). The article analyse Brazil's constitutions and ordinary legislations about the subject in study, to understand such changes, based on the federal model. The conclusion is that there was some sort of improvements on allocating resources, but the tendency of conservative governments not to prioritize this area in their agendas affects deeply the right to a proper education and its financing.

Key words: Federalism. Financing of Education. Federated entities.

\section{INTRODUÇÃo}

O presente artigo tem como objetivo analisar a evolução das competências dos entes federados quanto ao financiamento da educação pública no Brasil, a partir do momento em que o país passa a ser uma república federativa. Tal tema é relevante, uma vez que a educação pública é um direito assegurado aos cidadãos brasileiros pela Constituição Federal de 1988, em seu artigo 6º , caput. Como um direito social que necessita, em diversos aspectos, da ação programática do Estado, a sua tutela e efetivo gozo se dá por meio de políticas públicas. Dessa forma, a plena realização do direito à educação depende do direcionamento de recursos públicos a essas políticas e pela definição do papel dos entes federados na efetivação desse direito.

Sendo o Brasil um Estado federado, ou seja, um Estado com entes que possuem autonomia e são submetidos a um poder central, geral e soberano - em oposição ao modelo de Estado unitário - há não somente a repartição de poder político pelo território nacional, com diferentes níveis de poder, mas também de competências arrecadatórias, realizando assim o chamado federalismo fiscal. Neste sentido, há a divisão das alçadas dos entes também no que tange ao financiamento e gestão da educação pública básica. Porém, essa repartição não foi a mesma ao 
longo da história da república brasileira, o que refletiu em avanços e retrocessos no gozo desse direito.

Logo, o presente artigo abordará a história do financiamento da educação pública básica no Brasil, desde o nascimento da República Brasileira até os dias atuais, com o objetivo de não somente construir uma linha temporal que expõe as mudanças ocorridas ao longo dos anos, mas também de apontar, enquanto hipótese, uma sensível melhora do financiamento da educação, principalmente se comparados o estado de coisas da Ditadura Militar com o período após a Constituição de 1988.

0 presente artigo se dividirá em cinco partes, sendo cada uma delas relacionada a um momento histórico distinto, e analisará as legislações constitucionais e infraconstitucionais (quando pertinentes ao tema) que demonstram como se caracterizava o financiamento da educação pública. Primeiramente, abordaremos a República Velha, seguida pela Era Vargas e do período anterior ao estado de exceção; em seguida, trataremos do período da Ditadura Militar e, posteriormente, dos anos da redemocratização, finalizando a análise com a exposição do Fundo de Manutenção e Desenvolvimento da Educação Básica e de Valorização dos Profissionais da Educação (FUNDEB) e a posterior Proposta de Emenda Constitucional 241, aprovada em 2016, resultando na EC 95/2016. Ao final, são apresentadas as conclusões alcançadas por este estudo acerca de seu objeto.

\section{A EDUCAÇÃo BÁSICA NA REPÚBLICA VELHA}

Com a mudança do sistema político no Brasil da monarquia para a república, a nova Constituição, promulgada em 1891, passou a estabelecer as diretrizes do novo governo. Quanto a educação, não houve alterações significativas no período se comparado ao Império: a postura da União em relação à educação pública continua sendo absenteísta, mantendo a situação precária da escolarização no país ${ }^{1}$. Nesse momento, a União reafirmou o dever da família de se responsabilizar pela Educação Básica dos filhos, e assumiu para si o dever de regular apenas o ensino superior: 
Art.34 - Compete privativamente ao Congresso Nacional:

30. legislar sobre a organização municipal do Districto Federal, bem como sobre a polícia, o ensino superior e os demais serviços que na Capital forem reservados para o Governo da União; (BRASIL, 1891)

Mesmo após a proclamação da República, pouco mudou se comparado à época do Império, sendo o financiamento dos sistemas de ensino público um assunto preterido pela União. Durante o período imperial, e que se estendeu até República Velha, utilizou-se o Ato Adicional de 1834 para a definição do papel dos Estados (anteriormente denominados de Províncias) e Municípios (CURY, 2001, p. 73). Estes entes eram os responsáveis por estabelecer o financiamento dos seus sistemas de educação, a partir das dotações orçamentárias (MENEZES, 2006, p. 9).

Os governos estaduais passaram a conceder subvenções aos seus municípios, tendo como critério geral de distribuição de tais recursos a população local, o número de escolas providas e as vagas existentes (WERLE, 1997, p.102); as subvenções subsistiram até o ano de 1935 e consistiram em transferências de recursos estaduais para escolas municipais.

Adicionalmente, os Estados utilizavam as subscrições públicas, espécies de doações feitas por particulares, que apelavam para a boa vontade da população, com o intuito de obter recursos para a construção de estabelecimentos escolares, sob o discurso de dificuldade de obtenção de verbas (WERLE, 1997, p.22).

Ainda que o sistema de subvenções tenha perdurado até 1935 (ou seja, nos anos iniciais da Era Vargas), durante a Revisão Constitucional de 1926, o então deputado Afrânio Peixoto propôs uma vinculação constitucional de recursos para a educação, voltada para o ensino primário e secundário, com direção e custeio pelos Estados, através de um fundo especial, para desenvolver a educação de maneira mais uniforme (MENEZES, 2006, p. 15). Entretanto, essa emenda acabou por não ser votada e, no final, a Revisão de 1926 não trouxe alterações relevantes quanto ao custeio da educação.

Durante o início da República Velha, não havia o entendimento de que a Educação Básica era responsabilidade do governo federal, dado que este foi o período de maior descentralização no federalismo brasi- 
leiro, sendo maior a atuação dos Estados e Municípios. Ainda assim, a maior parte do financiamento, como será visto a seguir, era proveniente de recursos voluntários e, quando tais recursos eram estatais, não havia maior definição quanto às fontes de arrecadação a serem destinadas.

\section{O FINANCIAMENTO PÚBLICO EDUCACIONAL DA ERA VAR- GAS ATÉ O GOLPE DE 1964}

Com o fim da República Velha² e o início da Era Vargas, em 1930, diversas foram as mudanças na educação pública, com um enfoque deliberado no ensino secundário e superior em detrimento do ensino primário. Houve, na primeira fase do regime varguista, uma atenção muito maior à educação nesse momento, inclusive como parte de uma agenda ideológica que o governo dessa época possuía (VASCONCELOS, 2013, p. 27). Dentre outras mudanças ocorridas, estava a criação do Ministério da Educação e da Saúde Pública, os projetos de reforma educacional oriundos da sociedade civil e a Constituição Federal de 1934 (PALMA FILHO, 2005, p.2).

A Constituição Federal de 1934 estabeleceu com maior clareza o papel dos entes federativos no financiamento da Educação Básica. Em seu artigo 156, determinava que a União e os Municípios aplicariam pelo menos 10\% e os Estados e Distrito Federal ao menos 20\% da receita obtida com impostos, para a manutenção e desenvolvimento dos sistemas educacionais. 0 parágrafo único determinava que a União deveria reservar, anualmente, ao menos $20 \%$ das cotas destinadas à educação no orçamento anual para o ensino em zonas rurais (BRASIL, 1934).

Entretanto, não havia definição de quais impostos deveriam ser destinados ao financiamento da educação. Paralelamente, há a figura dos fundos de educação, que destinavam auxílios a alunos necessitados (PALMA FILHO, 2005, p.10). A determinação, de forma geral, era de que a União, os Estados e o Distrito Federal reservassem parte de seus bens imóveis para a formação de fundos de educação, a partir da alienação desse patrimônio (BRASIL, 1934). 
Com relação às competências administrativas para a gestão dos níveis educacionais, à União cabia privativamente traçar as diretrizes da educação nacional, conforme artigo 5o, inciso XIV, bem como "fixar o plano nacional de educação, compreensivo do ensino de todos os graus e ramos, comuns e especializados; e coordenar e fiscalizar a sua execução, em todo o território do País", de acordo com o artigo 150, "a” (BRASIL, 1934).

Já aos Estados e Distrito Federal, competia a organização e manutenção dos sistemas educativos, com respeito às diretrizes elaboradas pela União. 0 texto constitucional não explicitava o papel dos Municípios (BRASIL, 1934).

A Constituição de 1934 também adotou, em seu artigo 152, a figura do Conselho Nacional da Educação (originalmente criado em 1931 pelo Decreto $\mathrm{n}$ - 19.850). A sua finalidade era elaborar o plano nacional de educação, a ser aprovado pelo Poder Legislativo, sugerir ao Governo medidas que julgasse necessárias para a melhor solução dos problemas educacionais, bem como a distribuição adequada dos fundos especiais para a educação. Os Estados e o Distrito Federal deveriam estabelecer Conselhos de Educação com funções similares, nessas esferas administrativas (BRASIL, 1934).

Apesar da presença mais ativa da União em relação ao fomento da educação, o posterior endurecimento do governo de Getúlio Vargas levou à uma alteração legal profunda, promovida pela Constituição de 1937, que retirou a vinculação de recursos para a educação e diminuiu o papel da União. Nesse momento constitucional, a educação é destacada primordialmente como dever dos pais, com a colaboração subsidiária ou principal do Estado, conforme artigo 125 (BRASIL, 1937).

Neste sentido, o artigo 130 assevera que:

O ensino primário é obrigatório e gratuito. A gratuidade, porém, não exclui o dever de solidariedade dos menos para com os mais necessitados; assim, por ocasião da matrícula, será exigida aos que não alegarem, ou notoriamente não puderem alegar escassez de recursos, uma contribuição módica e mensal para a caixa escolar. (BRASIL, 1937)

A caixa escolar já havia sido utilizada anteriormente no Brasil, na época imperial, por sugestão do político Leôncio de Carvalho (MOACYR, 
1937, p. 182). 0 intuito desse mecanismo era a inserção de alunos mais pobres nas escolas, mesmo que se pudesse alegar que, com esse dispositivo, o ensino primário não fosse essencialmente "gratuito".

Percebe-se, portanto, que durante o segundo momento da Era Vargas houve uma incerteza da destinação de recursos a este setor. Diante do silêncio da Constituição de 1937, foi reintroduzida a vinculação de recursos no início dos anos de 1940, através do Decreto Lei no 4.958/42, que instituiu o Fundo Nacional do Ensino Primário, e do Decreto Lei no 5.239/43, que ratificou o Convênio do Ensino Primário.

O Convênio estabeleceu que os Estados da federação que fossem conveniados, aplicariam em 1944,15\% da receita de impostos e, quanto aos municípios, $10 \%$. Esses percentuais aumentariam em $1 \%$ ao ano até atingirem 20\% e 15\%, respectivamente, no ano de 1949 (BRASIL, 1943). Por sua vez, os recursos do Fundo seriam obtidos através de um adicional de 5\% sobre taxas do imposto de consumo de bebidas, instituído em 1938.

Porém, com a deposição de Vargas em 1945 e a elaboração de uma nova Constituição, retornam as disposições de vinculação de recursos (DE JESUS, 2010, p. 217). A Constituição de 1946 determinou, em seu artigo 169, a destinação de nunca menos de $10 \%$ pela União para o ensino básico. Quanto aos Estados, Distrito Federal e Municípios, deveriam ser vinculados ao menos $20 \%$ dos impostos sem, entretanto, ficar explícito quais impostos seriam atingidos.

Ao realizar uma análise global sobre o tema, apesar do forte crescimento econômico no Brasil no período entre 1930 e 1964 (cerca de $5,6 \%$ ao ano) e do retorno das vinculações de recursos à Constituição, o investimento não foi o suficiente para erradicar o analfabetismo, já que em 1950, cerca de 49\% da população acima de 15 anos era analfabeta (KANG, 2011, p. 574). Ainda segundo Kang (2011, p. 574) esse período foi marcado por alta concentração das decisões da União sobre a educação, impedindo a participação ativa de Estados e Municípios quanto o financiamento da educação.

Ainda que a segunda fase do governo Vargas tenha retirado do texto constitucional o percentual mínimo a ser aplicado em Educação Básica, durante a primeira fase de seu governo, houve uma sensível mudança do papel da União, pois é a primeira vez (1934) que este ente passa a ser 
incluído como responsável pela educação primária e secundária, inclusive fomentando a sua universalização.

Após a entrada em vigor da Constituição de 1946, iniciaram-se os debates sobre uma lei específica para determinar as diretrizes que guiariam a educação. Nesse meio tempo, Anísio Teixeira defendeu a elaboração de um Fundo de Educação que muito se assemelhava ao FUNDEB. Na sua ideia original, cada Estado e Município se transformaria em órgãos autônomos, com orçamentos próprios, organização técnica e autonomia administrativa, para realizar a gestão de recursos para "o educando brasileiro" (TEIXEIRA, 1999, p.1).

No ano seguinte, a discussão da Lei de Diretrizes e Bases para a Educação Nacional (LDB) foi iniciada, mas somente em 1961 foi finalizada e aprovada, tornando-se a Lei no 4.024/61. Tal se deu em função das disputas políticas em torno da lei, que foi arquivada em 1949, voltando a ser discutida em 1957 (MOREIRA; BARROS, 2015, p. 441). Anísio Teixeira foi, nesse período, fervoroso defensor de maiores definições quanto ao financiamento do ensino. Segundo Jani Moreira e Fabiana Barros:

Aprovada a Lei no 4.024/61 (BRASIL, 1961), Anísio Teixeira, como Conselheiro do Conselho Federal de Educação, retomou as discussões sobre o financiamento do ensino e prescreveu sobre as bases preliminares para o plano de educação referente ao fundo nacional do ensino primário (1961) em atendimento ao parágrafo $2^{\circ}$ do artigo 92 da Lei de Diretrizes e Bases no 4.024/61, quando define que "O Conselho Federal de Educação elaborará, para execução em prazo determinado, o Plano de Educação referente a cada Fundo" (BRASIL, 1961, p. 3). As prescrições de Teixeira (1961) tinham a preocupação de estabelecer direcionamentos para a concretização da política de 'colaboração' entre os três entes do governo (2015, p. 441).

A LDB no 4.024/61 atribuiu aos conselhos de educação, Federal e Estadual, o poder de decisão sobre o funcionamento da educação (artigos 8 e 9). A lei instituiu a porcentagem mínima de $12 \%$ de receitas da União a serem por ela aplicadas. Aos Estados, Distrito Federal e Municípios, a porcentagem estabelecida foi de $20 \%$. Além disso, a lei instituiu os fundos nacionais do ensino primário, ensino médio e ensino superior (BRASIL, 1961). Entretanto, como será visto no próximo tópico, a LDB sofreu graves retrocessos em função do governo ditatorial. 


\section{O FINANCIAMENTO PÚBLICO EDUCACIONAL NO PERÍODO DA DITADURA MILITAR}

Durante o governo de Juscelino Kubitschek, que durou de 1956 a 1960, houve uma oposição de forças dentro da sociedade que se agravou com os governos posteriores (de Jânio Quadros e João Goulart), culminando no golpe de Estado de 1964 e no início da ditadura comandada por militares. Essa alteração no modelo político do país teve consequências para a educação pública e o papel da União, dos Estados e dos Municípios como seus financiadores e gestores.

Segundo Saviani (2008, p. 295), as novas forças políticas que assumiram o poder encaravam a educação como um instrumento para o aumento da produtividade econômica. A escola primária deveria capacitar para a realização de atividades práticas, enquanto o ensino secundário deveria preparar os jovens para se tornarem os novos profissionais do país - com seu ingresso no ensino superior, era iniciada a preparação do quadro dirigente do Brasil (SOUZA, 1981, p. 67-68).

Ao mesmo tempo, houve vasto incentivo para que a iniciativa privada passe a fornecer a educação àqueles que podem pagar por ela. Inclusive é evidenciada (no artigo 168, III da Constituição de 1967) a preferência do Poder Público pelo setor privado, através da substituição de investimentos no ensino público pela concessão de bolsas de estudo para alunos, com posterior reembolso no caso do ensino superior (BRASIL, 1967). Saviani explica que

Esse enunciado foi reforçado na Emenda de 1969: "o Poder Público substituirá, gradativamente, o regime de gratuidade no ensino médio e no superior pelo sistema de concessão de bolsas de estudos, mediante restituição, que a lei regulará" (artigo 176, §3ํ, inciso IV). Como se vê, o que em 1967 era previsto apenas como uma possibilidade e circunscrito ao ensino superior, em 1969 se converte numa determinação incondicionada, estendida também ao ensino médio. (2008, p. 299)

Assim, o governo desse período possuía uma clara intenção de utilizar o aparato privado como principal encarregado pela prestação do serviço, e deve-se levar em conta que a Constituição de 1967 não possuía 
previsão sobre a responsabilidade do Estado em caso da má prestação desse serviço por atores privados.

Se por um lado as competências da União, dos Estados e Municípios com relação à gestão dos sistemas de ensino permaneceram (conforme o artigo 168, parágrafos e incisos), e apesar da tendência à utilização do aparato privado, por outro lado não há mais a previsão de vinculação de recursos destinados à educação.

A retirada da vinculação causou a oposição de educadores e membros do próprio governo, os quais trouxeram propostas de emendas que clamavam por um percentual mínimo de investimento em educação, mas que foram rejeitadas (MENEZES, 2006, p. 20). A revogação da vinculação foi sustentada pelo argumento de que a mesma não era compatível com o sistema orçamentário introduzido pela nova Constituição (HORTA, 2001, p. 219).

Somente dois anos depois a Emenda Constitucional no1 de 1969 garantiu que os Municípios destinassem ao menos $20 \%$ de sua receita tributária para o ensino primário. Porém, o governo central e os Estados continuaram sem previsão expressa de vinculação de recursos (BRASIL, 1969).

De qualquer forma, esse período foi marcado pela rápida expansão das redes de ensino público sem um investimento suficiente. Saviani (2008, p. 298) explica que:

Em consequência da exclusão do princípio da vinculação orçamentária, o governo federal foi reduzindo progressivamente os recursos aplicados na educação: "desceu de 7,60\% (em 1970), para 4,31\% (em 1975), recuperando-se um pouco em 1978, com 5, 20\%" (Vieira, 1983, p. 215). Assim, liberado da imposição constitucional, o investimento em educação por parte do MEC chegou a aproximadamente um terço do mínimo fixado pela Constituição de 1946 e confirmado pela LDB de 1961.

Dessa forma, o período ditatorial significou um retrocesso quanto aos investimentos reais para a educação pública, não somente pela tendência ao uso de instrumentos privados para a garantia desse direito, mas também pelos próprios interesses dos governos da época, que não entendiam a educação como uma prioridade e que, portanto, não se 
preocuparam em determinar recursos fixos para seu custeio. Com o fim da ditadura militar em 1985, há um processo de resposta a esse comportamento do Estado, como forma de garantir e resguardar direitos.

\section{DA REDEMOCRATIZAÇÃO ATÉ OS DIAS ATUAIS}

A partir da redemocratização e da promulgação da Constituição Federal de 1988 (BRASIL, 1988), foram feitos esforços para vincular uma parte dos recursos públicos à educação pública, em oposição ao período ditatorial.

Inicialmente, 0 artigo 6 o estabelece a educação como direito social (BRASIL, 1988). Tanto a União quanto os Estados, Distrito Federal e Municípios seriam responsáveis pela prestação dos serviços de educação (artigo 23, V), bem como pela legislação sobre a matéria (artigo 24, IX).

Segundo o artigo 208, o Estado como um todo prestará a educação através:

I - ensino fundamental, obrigatório e gratuito, inclusive para os que a ele não tiveram acesso na idade própria;

II - progressiva extensão da obrigatoriedade e gratuidade ao ensino médio; III - atendimento educacional especializado aos portadores de deficiência, preferencialmente na rede regular de ensino;

IV - atendimento em creche e pré-escola às crianças de zero a seis anos de idade;

V - acesso aos níveis mais elevados do ensino, da pesquisa e da criação artística, segundo a capacidade de cada um;

VI - oferta de ensino noturno regular, adequado às condições do educando; VII - atendimento ao educando, no ensino fundamental, através de programas suplementares de material didático-escolar, transporte, alimentação e assistência à saúde. (BRASIL, 1988)

Já o artigo 211 estabelece o regime de colaboração entre os sistemas de ensino dos entes federados. À União compete organizar e financiar o sistema federal, prestando assistência técnica e financeira aos outros entes. Os municípios atuarão prioritariamente no ensino fundamental 
e pré-escolar, enquanto os estados deverão cuidar do ensino médio (BRASIL, 1988).

0 artigo 212 prevê a vinculação anual de pelo menos 18\% das receitas resultantes de impostos no caso da União e, quanto aos demais entes, o mínimo de 25\%, compreendida aí a receita resultante de transferências, para a manutenção e desenvolvimento do ensino. Como fonte adicional de receita, foi estabelecida a contribuição social do salário-educação, sobre a qual falaremos mais adiante (BRASIL, 1988).

Entretanto, ainda que a nova Constituição estabeleça com maior exatidão as competências quanto à matéria e a vinculação de recursos, durante o espaço de tempo entre 1988 e a Emenda Constitucional no 14 e a Lei no 9.424 em 1996, ainda restaram dúvidas sobre quais recursos fiscais seriam utilizados, o que resultou na prestação de uma educação pública ineficaz (COSTA; MENEZES, 2014, p. 62). Diante disso, surgiu a necessidade de elaborar mecanismos que sanassem tais dificuldades.

\section{Fundo de Manutenção e Desenvolvimento do Ensino Fundamental e de Valorização do Magistério (FUNDEF)}

Durante a década de 1990, foi dada maior importância à descentralização da educação, com reforço ao papel dos municípios na prestação deste serviço; nesse ínterim, o Fundo de Manutenção e Desenvolvimento do Ensino Fundamental e de Valorização do Magistério (FUNDEF) foi formulado como uma medida para a injeção de recursos na educação, com foco em universalizar o ensino fundamental nas idades entre 7 e 14 anos (COSTA; MENEZES, 2014, p. 62), suprindo, então, a incerteza sobre quais recursos seriam utilizados. Como parte da adoção do Fundo, foi elaborado estudo, pelo Fundo Nacional de Desenvolvimento da Educação (FNDE) a fim de compreender como se dava a arrecadação de impostos e o uso dos recursos disponíveis para o investimento em educação nos entes federados. Viu-se a grande diferença entre redes municipais e estaduais, quanto ao financiamento da Educação Básica. Os investimentos eram heterogêneos, existindo discrepâncias entre Estados e entre municípios de um mesmo Estado (MONLEVADE; FERREIRA, 1997, p. 15). 
Com a Emenda Constitucional no 14 de 1996, o artigo 60 do ADCT ${ }^{3}$ instituiu a aplicação de pelo menos $50 \%$ dos recursos vinculados para a educação na redução do analfabetismo e universalização do ensino fundamental (BRASIL, 1996a). Entretanto, a União não seguiu estes preceitos, o que acarretou em prejuízo ao desenvolvimento dessas áreas. Segundo Costa e Menezes:

De acordo com Oliveira (2001), a União computava os 50\% a serem investidos no ensino fundamental como resultado da média da aplicação dos diferentes Entes Federados, e não como uma responsabilidade associada a cada um deles. Como os Estados e Municípios aplicavam nesse nível de ensino percentuais acima do mínimo estabelecido (respectivamente 68,4 e 59\%, para o ano de 1995), acabaram por compensar a irregular aplicação da União (22,9\%), denunciada pelo Tribunal de Contas da União (TCU) quanto à inconstitucionalidade dos gastos educacionais. (COSTA; MENEZES, 2014, p. 63).

Diante dessa situação, houve uma redução da participação da União, de 50\% para, no mínimo, 30\%, e a determinação aos Estados, Distrito Federal e Municípios que destinassem ao ensino fundamental público, por 10 anos, 60\% dos 25\% dos impostos vinculados à Manutenção e Desenvolvimento do Ensino (MDE), em conformidade com os artigos 70 e 71 da LDB:

Art. 70. Considerar-se-ão como de manutenção e desenvolvimento do ensino as despesas realizadas com vistas à consecução dos objetivos básicos das instituições educacionais de todos os níveis, compreendendo as que se destinam a:

I - remuneração e aperfeiçoamento do pessoal docente e demais profissionais da educação;

II - aquisição, manutenção, construção e conservação de instalações e equipamentos necessários ao ensino;

III - uso e manutenção de bens e serviços vinculados ao ensino;

IV - levantamentos estatísticos, estudos e pesquisas visando precipuamente ao aprimoramento da qualidade e à expansão do ensino;

V - realização de atividades-meio necessárias ao funcionamento dos sistemas de ensino;

VI - concessão de bolsas de estudo a alunos de escolas públicas e privadas; 
VII - amortização e custeio de operações de crédito destinadas a atender ao disposto nos incisos deste artigo;

VIII - aquisição de material didático-escolar e manutenção de programas de transporte escolar.

Ao mesmo tempo, não são considerados despesas com manutenção e desenvolvimento do ensino, conforme o artigo 71, aquelas realizadas com pesquisas, quando não vinculadas às instituições de ensino e, se realizadas fora da instituição, não visem o aprimoramento da qualidade do ensino; a subvenção a instituições, sejam públicas ou privadas, de caráter desportivo, assistencial ou cultural; a formação de quadros especiais para a administração pública; programas suplementares de alimentação e saúde; obras de infra-estrutura, ainda que beneficiem direta ou indiretamente a rede escolas e o gasto com pessoal docente e trabalhadores da educação em desvio de função ou atividade alheia ao desenvolvimento do ensino (BRASIL, 1996).

Segundo Pinto (1999, p. 90), essa alteração estabeleceu uma maior fluidez ao manejo dos recursos, por parte da União, já que essa porcentagem não precisava estar obrigatoriamente atrelada à receita de impostos. A União poderia utilizar, por exemplo, recursos do salário-educação e do Fundo de Amparo ao Trabalhador para atingir o mínimo de $30 \%$ a ser investido no ensino fundamental, mas isso significou também que não estavam sendo injetados novos recursos para a educação.

Dentro desse contexto, em que há um desnível do investimento de recursos para a educação, surge o FUNDEF, que foi instituído pela Lei no 9.424 de 1996, e estabeleceu a gestão dos recursos a partir do modelo de fundo, tratando não somente da arrecadação tributária e do investimento de Estados e Municípios, mas também de transferências da União para estes entes, a título de complementação, quando o valor mínimo por aluno não fosse atingido pelo ente federado.

O fundo foi composto de 15\% sobre as receitas do Fundo de Participação de Estados e Municípios (FPE e FPM, respectivamente), imposto sobre a circulação de mercadorias e serviços (ICMS), recursos relativos à desoneração de exportações e imposto sobre produtos industrializados, proporcional às exportações (BRASIL, 1996). Os valores eram remetidos 
ao fundo e, posteriormente, repartidos entre Municípios dentro de um mesmo Estado.

0 artigo 60 da Lei $n^{0} 9.424$ indicava que o repasse era efetuado da seguinte forma: o valor per capita médio nacional era o parâmetro utilizado para a determinar o valor mínimo, a ser repassado através de decreto presidencial. Esse valor não deveria ser inferior ao quociente entre as receitas previstas para o FUNDEF e as matrículas totais do ano anterior, no ensino fundamental, somadas às estimativas de novas matrículas (BRASIL, 1996).

Para aferir a quantidade de matrículas nas respectivas redes, o MEC, através do Instituto Nacional de Estudos e Pesquisas Educacionais Anísio Teixeira (INEP), realizava o censo educacional, anualmente disponibilizado no Diário Oficial da União (DOU) (COSTA; MENEZES, 2014, p.67). Conforme explica Gomes (2009, p. 667) a operacionalização do FUNDEF era dividida em quatro etapas:

[...] 1) retenção de valores no fundo estadual; 2) cálculo do valor médio aluno/ano em cada estado; 3 ) redistribuição de acordo com o número de matrículas feitas no ensino fundamental; e 4) complementação da União nos Estados e Municípios abaixo da média nacional (definida anualmente pelo governo federal).

O FUNDEF estabeleceu a destinação de recursos federais aos Estados cujo gasto aluno/ano estivesse abaixo do mínimo exigido. Segundo Sobreira e Campos:

O valor necessário para que as unidades federadas mais carentes atinjam o gasto anual mínimo por aluno é repassado pelo governo federal a fundo perdido (Negri, 1997a e b). Importante ressaltar que tal gasto mínimo não necessariamente corresponde ao valor efetivamente aplicado por aluno na educação pública fundamental, podendo representar um valor potencial ou mínimo, dependendo da disponibilidade de receitas em cada estado. $(2008,331)$

A valorização do magistério se dava através da destinação obrigatória de pelo menos $60 \%$ dos recursos do Fundo à remuneração de professores do ensino fundamental regular, podendo também ser destinada ao 
pagamento de profissionais da educação especial, indígena e supletiva. Os outros 40\% não possuíam destinação específica (BRASIL, 1996).

A implantação do FUNDEF ocorreu automaticamente a partir de 1998, com contas únicas e específicas no Banco do Brasil (BRASIL, 1996). Pelo Decreto no 2.264/97, os valores passaram a obedecer aos prazos das fontes primárias para a composição do Fundo, a partir de fluxos semanais, decendiais e mensais, conforme Art. 2oㅡ, parágrafo 5ํ․ A transferência poderia ser efetuada para qualquer banco público, desde que houvesse uma conta vinculada ao FUNDEF.

Conforme descrição de Kolslinski:

A parcela de recursos do Fundo, originária do ICMS, é creditada semanalmente (periodicidade de repasses do ICMS), de acordo com o calendário de cada Estado [...] A parcela originária do FPE, FPM e IPIexp é creditada a cada decênio (sic) do mês, ou seja, dias 10, 20 e 30 (periodicidade de repasses dessas transferências) [...] A parcela originária da Desoneração das Exportações (Lei Complementar no 87/96), e a transferência relativa à complementação da União, são creditadas ao final de cada mês. (2000, p.73)

Como a redistribuição dos recursos do Fundo era feito dentro do território de uma mesma unidade da federação, repartindo entre os Municípios, alguns municípios contribuíram mais e receberam menos. Entretanto, como apontado por Vazquez (2003, p. 58) em 1998, 2.703 municípios no país ganharam recursos com o Fundo, correspondendo a $81 \%$ das matrículas de toda a rede municipal, enquanto 2.803 sofreram perdas, mas estes representavam apenas 19\% das matrículas da rede municipal.

Neste sentido, um dos principais objetivos do FUNDEF foi a redução das disparidades regionais e a melhoria na cooperação federativa visando a promoção do MDE do ensino fundamental público, a universalização do ensino e o aumento da qualidade do serviço ofertado.

Entretanto, a iniciativa não foi isenta de críticas: (1) maior concentração de recursos no ensino fundamental em detrimento das outras etapas e modalidades de ensino que compõem a Educação Básica; (2) ausência de dinheiro "novo" para o sistema educacional brasileiro como um todo; e (3) a pequena contribuição da União para o Fundo. Nova propostas buscaram corrigir tais erros. 


\section{O Fundo de Manutenção e Desenvolvimento da} Educação Básica e de Valorização dos Profissionais da Educação (FUNDEB)

Diante dessas questões, o FUNDEB foi elaborado como um programa para a substituição do FUNDEF. A primeira proposta apresentada com esse fim foi a PEC no 112/99 (BRASIL, 1999), que sugeriu a abrangência de todas as matrículas da Educação Básica pelo novo fundo, não priorizando apenas o ensino fundamental. Porém, essa proposta não chegou a ser discutida pela Câmara dos Deputados. Outras propostas que objetivaram corrigir as falhas do FUNDEF foram apresentadas posteriormente, principalmente a insuficiência de recursos, devido à pouca participação da União (MENDES, 2012, p. 394), constituindo esses os principais problemas deste Fundo.

Em 2004, o Ministério da Educação realizou discussões sobre a proposta que originaria o FUNDEB (BRASIL, 2004), com a participação de gestores estaduais e municipais da educação, representantes da União Nacional dos Dirigentes Municipais da Educação (UNDIME), Confederação Nacional dos Trabalhadores em Educação (CNTE) e a Campanha Nacional pelo Direito à Educação (MENDES, 2012, p. 395). Ao final dessas discussões, a proposta do Fundo foi enviada ao Congresso Nacional.

Uma vez no Congresso, foi alcançado certo consenso sobre as características positivas do FUNDEF, e que deveriam ser preservados no FUNDEB, como a natureza contábil do fundo, as contas únicas e específicas com repasses automáticos e a limitação do Fundo ao âmbito de cada Estado, sem redistribuição de recursos para além das fronteiras estaduais (MARTINS, 2009, p.199).

Deveria também ser preservada a aplicação de diferentes ponderações para etapas e modalidades de ensino e tipos de estabelecimento; o controle social e acompanhamento exercido por conselhos nas três esferas federativas; a destinação de ações de manutenção e desenvolvimento do ensino na Educação Básica; a possibilidade de retificação de dados do Censo por demanda dos entes federados e a complementação da União (MARTINS, 2009, p.199). 
Ao final, a proposta do novo Fundo foi aprovada, estabelecendo como objetivo aumentar o número de alunos financiados, passando de 31,2 para 47,7 milhões, estimativa de aumento do montante de recursos para a educação de $\mathrm{R}$ \$28,7 para $\mathrm{R}$ \$ 51 bilhões e da participação da União através das complementações, de R 446 milhões para 1,3 bilhão e aumento em $80 \%$ no gasto com a remuneração dos profissionais da Educação Básica (ROSSINHOLI, 2008, p. 130).

A proposta oficial foi apresentada ao Congresso Nacional pela Presidência da República, sob a forma de PEC no 415/2005 (BRASIL, 2005). 0 texto final estabeleceu que o termo do FUNDEB se daria 14 anos após sua entrada em vigor. Foram incluídas as creches para receberem recursos pelo fundo, bem como destinação obrigatória de 60\% dos recursos ao pagamento dos profissionais da educação (ROSSINHOLI, 2008, p.134).

Após deliberações no Poder Legislativo, a PEC no 415/2005 foi aprovada e, ao final, foram realizadas alterações quanto a composição do fundo e valores para os anos iniciais: ao quarto ano, os valores repassados pela União deveriam atingir 10\%, com a atualização desses recursos e a consideração, ano a ano, das matrículas da Educação Infantil, Ensino Médio e Educação de Jovens e Adultos (BRASIL, 2006).

A composição do fundo é feita a partir da transferência de $20 \%$ dos impostos indicados como fonte de obtenção de recursos. $10 \%$ do valor total do Fundo será a contribuição da União a partir do quarto ano e o valor por aluno do ensino fundamental não poderá ser inferior ao estabelecido pelo FUNDEF em 2006 (BRASIL, 2007). Quanto aos outros $40 \%$ dos recursos obtidos, é vedada a sua utilização em despesas que não sejam consideradas pela Lei de Diretrizes e Bases da Educação como MDE (BRASIL, 1996).

Para a efetivação dos repasses, é utilizado o método de cálculo do salário educação, feita com base no número de alunos das redes estadual e municipal. A título explicativo, o salário educação é a contribuição social arrecadada por empresas à Receita Federal com fins de suplementar as despesas com educação no país como um todo. Do total de $100 \%$ arrecadado, $10 \%$ é repassado ao FNDE, para programas e projetos de incremento da Educação Básica. 30\% é repassado à União, para aplicação de ações que visam a diminuição de desigualdades educacionais entre 
Estados e Municípios, enquanto os outros $60 \%$ são divididos entre Estados e Municípios, para o financiamento de programas, projetos e ações voltados para a Educação Básica, conforme artigo 212, § 6 da Constituição Federal (BRASIL, 1988).

É utilizado o censo escolar mais atualizado, elaborado pelo INEP, considerando as matrículas presenciais efetivas, como forma de consolidação do repasse de recursos por número de alunos. Apesar dos dados do censo serem defasados, pois dizem respeito ao ano anterior ao que ocorrerão os repasses, a Lei no 11.494/07 estabeleceu, em seu artigo 9, § 4ํㅡㅁ a possibilidade de Estados, Municípios e Distrito Federal apresentarem recurso para a retificação desses dados, até 30 dias após a publicação destes.

Segundo o inciso II do art. 60 do ADCT, alterado pela EC no 53 de 2006, a União deverá contribuir com pelo menos $10 \%$ e até $30 \%$ dos recursos obtidos conforme os incisos I, II e III do artigo $155^{4}$, II do artigo $157^{5}$, II, III e IV do artigo $158^{6}$ e "a" e "b" do inciso I, II do artigo $159^{7}$. Isso implica dizer que, desses itens constantes dos artigos citados, pelo menos $10 \%$ obrigatoriamente integrarão o FUNDEB, e dentro desse montante estará a complementação da União, se necessário.

Além disso, uma parte da complementação da União (até 10\% sobre o total do valor anual) poderá ser repassado para os Fundos através de programas voltados para a melhoria da Educação Básica, levando-se em consideração:

I - a apresentação de projetos em regime de colaboração por Estado e respectivos Municípios ou por consórcios municipais;

II - o desempenho do sistema de ensino no que se refere ao esforço de habilitação dos professores e aprendizagem dos educandos e melhoria do fluxo escolar;

III - o esforço fiscal dos entes federados;

IV - a vigência de plano estadual ou municipal de educação aprovado por lei. (BRASIL, 2007, on-line)

Por outro lado, a União não poderá aplicar mais do que 30\% dos recursos definidos no artigo 212 da Constituição Federal com o intuito de complementar o FUNDEB; os montantes fixos de complementação 
deverão obrigatoriamente ser atualizados, para manter o valor real e, finalmente, o descumprimento dos incisos $\mathrm{V}^{8}$ e VII ${ }^{9}$ do caput do art. 60 do ADCT importarão crime de responsabilidade das autoridades competentes (Presidente da República e Ministro da Educação).

A receita do fundo, no âmbito estadual e do Distrito Federal, é composta de $20 \%$ sobre o ICMS, IPVA, imposto de transmissão causa mortis, arrecadação de impostos instituídos pela União no exercício da competência atribuída pelo artigo 154, I da Constituição Federal, impostos sobre a venda de produtos industrializados devidos aos fundos de participação dos estados, Distrito Federal e municípios e arrecadação de impostos sobre propriedade territorial rural, de imóveis situados nos municípios.

Uma vez obtidos os recursos, o Estado e os Municípios irão transferi-los para o Banco do Brasil ou Caixa Econômica Federal, e a instituição financeira onde os valores foram entregues depositará os recursos na conta específica do Estado e dos Municípios. 0 mesmo ocorre quando o Distrito Federal realiza a sua arrecadação, e quando a União realiza a entrega da complementação. Importante ressaltar, ainda, que esses valores deverão constar do orçamento de todos entes.

Emenda Constitucional no 95 de 2016: impactos sobre o financiamento da educação

Apesar do manifesto avanço da legislação brasileira em relação ao financiamento da educação pública básica, esse objeto é afetado diretamente pelas crises políticas e voltou a sofrer com retrocessos recentemente.

A Emenda Constitucional no 95 de 2016, de autoria do Poder Executivo, institui o novo regime fiscal, o qual promove a limitação dos gastos primários da União (ou seja, as despesas que não consideram os efeitos financeiros, decorrentes dos juros). Seu objetivo é alterar, dentro do Ato de Disposições Constitucionais Transitórias (inserindo os artigos 101 a 109), alguns gastos primários do poder público federal, como forma de reequilibrar as contas públicas.

Entretanto, alguns gastos estão excluídos desta limitação, especialmente aqueles decorrentes das despesas constitucionais da União para Estados e Municípios. Além disso, os gastos com educação e saúde, segundo seu conteúdo, deverão crescer, no mínimo, no mesmo ritmo da inflação. 0 teto da limitação vigorará por vinte anos, podendo ser alterado 
por iniciativa do Presidente da República a partir do décimo ano, através de lei complementar.

0 artigo 107 do ADCT recém-alterado estabelece que os limites deverão ser observados pelos seguintes Poderes e órgãos:

I - o Poder Executivo;

II - o Supremo Tribunal Federal, o Superior Tribunal de Justiça, o Conselho Nacional de Justiça, a Justiça do Trabalho, a Justiça Federal, a Justiça Militar da União, a Justiça Eleitoral e a Justiça do Distrito Federal e Territórios;

III - o Senado Federal, a Câmara dos Deputados e o Tribunal de Contas da União;

IV - o Ministério Público da União e o Conselho Nacional do Ministério Público; e

V - a Defensoria Pública da União (BRASIL, 2016).

A partir do ano de 2017, o limite de gastos corresponderá à despesa primária de 2016, incluindo os restos a pagar e qualquer operação que afete o resultado primário, corrigida em 7,2\%. Para os demais anos, o limite corresponderá ao limite do ano imediatamente anterior, corrigido pela inflação medida pelo IPCA (ou de outro índice que vier a substituí-lo) acumulada em doze meses encerrada em junho do exercício anterior a que se refere a lei orçamentária.

Dessa forma, em 2018, por exemplo, o limite dos gastos será equivalente às despesas primárias para 2017, corrigido pela inflação medida pelo IPCA obtido entre julho de 2016 e junho de 2017. Se, no ano de 2019 , os gastos ficarem abaixo do valor gasto em 2016, essa poupança não precisará ser repetida em 2020. E se os gastos extrapolarem o teto em determinado ano, isso não autoriza o aumento no ano seguinte.

Entretanto, algumas despesas são excepcionadas destes limites:

i) As seguintes transferências constitucionais:

a. Participação no resultado da exploração de petróleo ou gás natural, de recursos hídricos para fins de geração de energia elétrica e de outros minerais ( $§ 1^{\underline{o}}$ do art. 20 da Constituição Federal - CF).

b. Decorrentes de repartição de receitas tributárias, conforme previsto nos arts. 157, 158, incisos I e II, e 159 da CF; 
c. Cotas estaduais e municipais da contribuição social do salário-educação (art. 212, § 6으, da CF);

d. Fundo Constitucional do Distrito Federal (inciso XIV do caput do art. 21 da CF);

e. Complementações do Fundeb (incisos V e VII do caput do art. 60 do ADCT);

f. Repartição do IOF-Ouro (art. 153, § 5o, da CF);

g. Transferência de impostos estaduais e municipais arrecadados pelo Simples Nacional (art. 146, parágrafo único, da CF);

1) Créditos extraordinários decorrentes de despesas imprevisíveis e urgentes, como de guerras, comoção interna ou calamidade pública (§ $3^{\circ}$ do art. 167 da CF);

2) Despesas com realizações de eleições pela Justiça Eleitoral; e

3) Despesas com aumento de capital de empresas estatais não dependentes. (BRASIL, 2016, grifo nosso)

O artigo 108 proposto pela PEC prevê a possibilidade de alteração dos limites a partir do décimo ano de sua vigência, com iniciativa do Presidente da República, em uma única vez por mandato, por meio de lei complementar. 0 art. 110 do ADCT dispõe sobre os investimentos mínimos em serviços públicos de saúde e em manutenção e desenvolvimento do ensino (MDE). Para 2017, os gastos mínimos nessas áreas corresponderão àqueles especificados no art. 198 da Constituição.

A consequência do disposto nesse art. 105 do ADCT será a elevação dos gastos mínimos com saúde de 13,7\% da Receita Corrente Líquida para 15\% em 2017. De 2018 em diante, o piso de gastos com saúde corresponderá ao piso do ano anterior, corrigido pelo IPCA, da mesma forma como será corrigido o total de gastos primários.

Em relação à educação, para 2017, o piso de gastos corresponderá ao atualmente praticado, conforme o caput do art. 212 da Constituição, ou seja, $18 \%$ da receita de impostos, líquida de transferências. A partir de 2018, o piso passa a ser corrigido pela inflação, nos moldes das demais despesas.

Umas das polêmicas da EC no 95 reside especialmente nesse ponto. Segundo Laura Carvalho (2016) a medida é extremamente problemática, pois ela não serve para estabilizar a dívida pública, já que a crise fiscal 
brasileira é uma crise de arrecadação. As despesas primárias, sujeitas ao teto, cresceram menos na gestão de Dilma Rousseff do que nos dois governos de Lula e no último mandato de Fernando Henrique Cardoso (CARVALHO, 2016).

Mas a arrecadação teve crescimento menor no governo Dilma que nos outros mandatos. A falta de receitas é explicada pela crise econômica e as desonerações fiscais sem contrapartida. 0 teto estabelecido por 20 anos não busca aumentar a arrecadação (CARVALHO, 2016).

O reajuste do valor das despesas pela inflação, por sua vez, poderá ter dois efeitos: se a inflação cai, pode haver crescimento real das despesas por alguns anos. Se a inflação continuar a crescer, não haverá investimento real. No longo prazo, quando a arrecadação e o PIB voltarem a crescer, a PEC será uma medida rígida demais (CARVALHO, 2016).

A PEC não preservará os gastos com educação. Segundo a economista, como essa área tinha um mínimo de despesas custeado pela arrecadação de impostos, vinculado a partir de um percentual, quando a arrecadação crescia, o mínimo crescia. Com a EC no 95, o mínimo passará a ser reajustado apenas pela inflação do ano anterior. Isso resulta no chamado "congelamento de gastos", o que é extremamente prejudicial, pois a população cresce, mas o investimento não (CARVALHO, 2016).

No mesmo sentido é o parecer da Consultoria de Orçamento e Fiscalização Financeira - COFF da Câmara dos Deputados. Segundo relatório, em 2017 não se vislumbram perdas de recursos para despesas na manutenção da educação (MDE). Mas, a partir de 2018, essa perda já passa a existir, e se acentua nos anos seguintes.

Adicionalmente, segundo o artigo 110, parágrafo I do ADCT, a partir do exercício financeiro de 2017, as aplicações mínimas de recursos a que se refere o caput do art. 212, da Constituição, corresponderão, em cada exercício financeiro, às aplicações mínimas referentes ao exercício anterior corrigidas pela variação do Índice Nacional de preços ao Consumidor Amplo (IPCA), publicado pelo Instituto Brasileiro de Geografia e Estatística (IBGE), para o período de janeiro a dezembro do exercício imediatamente anterior (BRASIL, 2016).

Para averiguar o gasto da União com essas despesas, o Tesouro Nacional elabora um demonstrativo das receitas e despesas com a 
MDE. No caso específico, a COFF analisou as despesas liquidadas, com acréscimo, ao final do exercício, do montante inscrito em restos a pagar não-processados, com base em informações de órgãos e entidades da Administração Pública (COFF, 2016, p. 3).

A tabela abaixo mostra os gastos com MDE, com a aplicação mínima de 18\% da Receita Líquida de Impostos, aplicação efetiva e a comparação com a metodologia da EC nำ95, se a regra tivesse sido aplicada em 2010 e vigência a partir de 2011:

\section{Tabela 1 - MDE X PEC 241/16 - SIMULAÇÃO 2010 A 2016}

\begin{tabular}{r|r|r|r|r|r|r|r|}
\hline EXERCícIO & $\begin{array}{c}\text { Receita Líq. } \\
\text { de Impostos } \\
\text { (RL) }\end{array}$ & $\begin{array}{c}\text { Aplicação } \\
\text { Mínima } \\
\text { (18\% da RL) }\end{array}$ & $\begin{array}{c}\text { Aplic.Mín. } \\
\text { pelo IPCA } \\
\text { (PEC) }\end{array}$ & $\begin{array}{c}\text { Diferença } \\
\text { (PEC e regra } \\
\text { atual) }\end{array}$ & $\begin{array}{c}\text { Aplicação } \\
\text { em MDE } \\
\text { (executado) }\end{array}$ & $\begin{array}{c}\text { Aplic.MDE } \\
\text { pelo IPCA } \\
\text { (PEC) }\end{array}$ & $\begin{array}{c}\text { Diferença } \\
\text { (PEC e regra } \\
\text { atual) }\end{array}$ \\
\hline (1) 2010 & 173,5 & 31,2 & 31,2 & & 33,7 & 33,7 & \\
\hline 2011 & 205,5 & 37,0 & 33,0 & $-4,0$ & 39,8 & 35,7 & $-\mathbf{4 , 1}$ \\
\hline 2012 & 218,8 & 39,4 & 35,2 & $-4,2$ & 56,0 & 38,0 & $-\mathbf{1 8 , 0}$ \\
\hline 2013 & 239,1 & 43,0 & 37,2 & $-5,8$ & 53,9 & 40,2 & $-\mathbf{1 3 , 7}$ \\
\hline 2014 & 245,5 & 44,2 & 39,4 & $-4,8$ & 56,8 & 42,6 & $-\mathbf{1 4 , 2}$ \\
\hline 2015 & 258,6 & 46,5 & 42,0 & $-4,5$ & 59,4 & 45,3 & $-\mathbf{1 4 , 1}$ \\
\hline (2) 2016 & 259,7 & 46,7 & 46,5 & $-0,3$ & 59,7 & 50,2 & $-9,6$ \\
\hline
\end{tabular}

Fonte: COFF, 2016.

Observa-se que a EC no 95 promoveria uma redução dos recursos aplicados à educação, e nem uma aplicação efetiva em MDE atingiria o piso constitucional de $18 \%$, estabelecido pelo artigo 212, exceto em 2016. Somente com a queda da arrecadação de impostos com inflação alta se verificaria uma melhora na aplicação dos recursos (COFF, 2016, p.4). Portanto, a tendência é que os recursos para o custeio da educação sejam diminuídos com o passar dos anos.

\section{CONCLUSÃO}

Conforme visto ao longo deste trabalho, a definição legal do financiamento da educação pública básica no Brasil é marcada por movimentos pendulares, que alternam entre avanços e retrocessos. Em retrospecto, é possível dizer que a Constituição de 1988 foi, dentro da história do país, a mais detalhada quanto ao tratamento que o Estado deverá dispensar a essa área. 
A partir da análise das diferentes constituições, é possível perceber que a União é o ente que, historicamente, está mais distante do financiamento da Educação Básica, concentrando, desde o início da República, o papel de financiador da educação superior. Com o advento da Constituição de 1988 e, posteriormente, o FUNDEF e FUNDEB, há um aumento da participação da União no repasse de recursos à educação infantil, fundamental e superior, especialmente para a superação de desigualdades regionais.

Se, por um lado o papel da União cresceu significativamente ao longo do período analisado, pode-se dizer que, quanto aos Estados e Municípios, estes tiveram um maior detalhamento de seu papel do custeio da educação, com a definição dos impostos a serem destinados, e uma diminuição da sua liberdade em aplicar tais recursos, em função do FUNDEB.

É possível também dizer que, em comparação com períodos anteriores, o FUNDEF e o FUNDEB representam uma verdadeira conquista do ponto de vista da segurança jurídica (quanto às fontes de custeio) e da equalização entre regiões. Isso se contrapõe de forma radical a instrumentos como a caixa escolar, utilizada durante a Era Vargas, pois retira do indivíduo a responsabilidade direta de custeio e a repassa para o Estado enquanto um dever a ser cumprido, inserindo definitivamente tal tema na agenda pública.

Ao mesmo tempo, é perceptível que há uma tendência a tornar o financiamento mais complexo e pormenorizado, em oposição às tendências do passado, onde o Estado brasileiro não estabelecia, com riqueza de detalhes, seu papel diante das políticas de educação. Com a criação dos Fundos para desenvolvimento da Educação Básica, é maior o envolvimento de todos os entes federados de forma coordenada.

Através das análises das constituições federais e de leis ordinárias através do tempo, também é possível apontar que governos brasileiros com tendências conservadoras possuem movimentos em direção a desvincularem e diminuírem os recursos disponíveis para a educação. 0 governo de Getúlio Vargas, durante a sua segunda fase, alterou a previsão constitucional de vinculação de recursos dos entes; o governo da ditadura militar realizou o mesmo em 1967.

Atualmente, com o governo de Michel Temer, embora não sendo possível atribuir-lhe caráter ditatorial, tendo em vista ter se tornado 
Presidente em razão do impeachment sofrido pela Presidente eleita Dilma Rousseff, conforme decisões do Supremo Tribunal Federal sobre a matéria ${ }^{10}$, possui uma inegável tendência a realizar ajustes fiscais sem a devida realização de estudos precisos dos impactos desses ajustes sobre os recursos para a educação. E, conforme apontado anteriormente, as previsões feitas sobre a EC 95/2016 provavelmente terão impactos negativos sobre o financiamento da educação, o que enfraquece o papel da União como financiadora da Educação Básica.

Portanto, é possível afirmar que atualmente existe maior certeza sobre o dever dos entes federados quanto ao custeio da educação pública, que resulta dos fundos de equalização, associados ao texto legal da Constituição de 1988.

Porém, uma melhor proteção constitucional e uma maior definição quanto aos recursos que serão destinados à educação não necessariamente resultarão em melhores indicadores, de forma geral. Como forma de aprofundamento desse tema, é necessário realizar pesquisa no sentido de comparar, ao longo dos anos, os impactos que essas medidas tiveram sobre os indicadores de qualidade da educação e indicadores sociais, levando em consideração as possíveis variáveis envolvidas.

Logo, o presente estudo, de cunho formal e com enfoque nas legislações constitucionais e ordinárias poderá ser futuramente complementado por estudos de caráter material e que visam investigar se, e em qual medida, a destinação de mais recursos auxilia na melhoria da educação pública básica.

\section{NOTAS}

1 Conforme afirmam Rezende Pinto e Adrião (2006, p. 25), após a expulsão dos Jesuítas do país, a educação passou a ser ofertada de forma não seriada, através de aulas régias. Em 1886, apenas cerca de $1,8 \%$ da população brasileira era escolarizada.

2 A República Velha compreende o período entre os anos de 1889 e 1930, quando as elites cafeeiras paulistana e mineira revezavam o cargo da presidência da República, movidas por seus interesses políticos e econômicos.

3 Art. 5 o É alterado o art. 60 do ADCT e nele são inseridos novos parágrafos, passando o artigo a ter a seguinte redação: Art 60. Nos dez primeiros anos da promulgação desta emenda, os Estados, o Distrito Federal e os Municípios destinarão não menos de sessenta por cento dos recursos a que se refere o caput do art. 212 da Constituição Federal, a manutenção e ao desenvolvimento do ensino fundamental, com o objetivo de assegurar a universalização de seu atendimento e a remuneração condigna do magistério. 
(...) § 6⿳0 A União aplicará na erradicação do analfabetismo e na manutenção e no desenvolvimento do ensino fundamental, inclusive na complementação a que se refere o $\S 3$, nunca menos que o equivalente a trinta por cento dos recursos a que se refere o caput do art. 212 da Constituição Federal.

4 Art. 155. Compete aos Estados e ao Distrito Federal instituir impostos sobre:

I - transmissão causa mortis e doação, de quaisquer bens ou direitos;

II - operações relativas à circulação de mercadorias e sobre prestações de serviços de transporte interestadual e intermunicipal e de comunicação, ainda que as operações e as prestações se iniciem no exterior;

III - propriedade de veículos automotores

5 Art. 157. Pertencem aos Estados e ao Distrito Federal:

II - vinte por cento do produto da arrecadação do imposto que a União instituir no exercício da competência que lhe é atribuída pelo art. 154, I.

6 Art. 158. Pertencem aos Municípios:

II - cinquenta por cento do produto da arrecadação do imposto da União sobre a propriedade territorial rural, relativamente aos imóveis neles situados, cabendo a totalidade na hipótese da opção a que se refere o art. 153, § $4^{\circ}$, III;

III - cinquenta por cento do produto da arrecadação do imposto do Estado sobre a propriedade de veículos automotores licenciados em seus territórios;

IV - vinte e cinco por cento do produto da arrecadação do imposto do Estado sobre operações relativas à circulação de mercadorias e sobre prestações de serviços de transporte interestadual e intermunicipal e de comunicação.

7 Art. 159. A União entregará:

I - do produto da arrecadação dos impostos sobre renda e proventos de qualquer natureza e sobre produtos industrializados, $49 \%$ (quarenta e nove por cento), na seguinte forma:

a) vinte e um inteiros e cinco décimos por cento ao Fundo de Participação dos Estados e do Distrito Federal;

b) vinte e dois inteiros e cinco décimos por cento ao Fundo de Participação dos Municípios;

II - do produto da arrecadação do imposto sobre produtos industrializados, dez por cento aos Estados e ao Distrito Federal, proporcionalmente ao valor das respectivas exportações de produtos industrializados.

8 V - a União complementará os recursos dos Fundos a que se refere o inciso II do caput deste artigo sempre que, no Distrito Federal e em cada Estado, o valor por aluno não alcançar o mínimo definido nacionalmente, fixado em observância ao disposto no inciso VII do caput deste artigo, vedada a utilização dos recursos a que se refere o $§ 5^{\circ}$ do art. 212 da Constituição Federal.

9 VII - a complementação da União de que trata o inciso V do caput deste artigo será de, no mínimo: a) $\mathrm{R} \$ 2.000 .000 .000,00$ (dois bilhões de reais), no primeiro ano de vigência dos Fundos; b) $\mathrm{R} \$ 3.000 .000 .000,00$ (três bilhões de reais), no segundo ano de vigência dos Fundos; $c$ ) $\mathrm{R} \$$ 4.500.000.000,00 (quatro bilhões e quinhentos milhões de reais), no terceiro ano de vigência dos Fundos; d) 10\% (dez por cento) do total dos recursos a que se refere o inciso II do caput deste artigo, a partir do quarto ano de vigência dos Fundos;

10 Cf. HC 134222 ED/DF; HC134315 AgR/DF; MS 34130 MC/DF; MS34131 MC/DF; MS34127MC/ DF; ADI 5498MC/DF. 


\section{REFERÊNCIAS}

BRASIL. [Constituição (1981)]. Constituição da República Federativa do Brasil de 1981. Disponível em: http://www.planalto.gov.br/ccivil_03/constituicao/constituicao91.htm. Acesso em: 18 fev 2017.

. [Constituição (1934). Constituição da República Federativa do Brasil de 1934. Disponível em: http://www.planalto.gov.br/ccivil_03/constituicao/Constituicao34.htm. Acesso em: 20 fev 2017.

. [Constituição (1937). Constituição da República Federativa do

Brasil de 1937. Disponível em: http://www.planalto.gov.br/ccivil_03/constituicao/constituicao37.htm. Acesso em: 20 fev 2017.

. [Constituição (1937). Constituição da República Federativa do Brasil de 1946. Disponível em: http://www.planalto.gov.br/ccivil_03/constituicao/constituicao46.htm. Acesso em: 21 fev. 2017.

. [Constituição (1967). Constituição da República Federativa do

Brasil de 1967. Disponível em: http://www.planalto.gov.br/ccivil_03/constituicao/constituicao67.htm. Acesso em: 22 fev 2017.

. [Constituição (1988). Constituição da República Federativa do Brasil de 1988. Disponível em: http://www.planalto.gov.br/ccivil_03/constituicao/constituicao.htm. Acesso em: 24 fev 2017.

. Emenda Constitucional no 1 de 17 de outubro de 1969. Disponível em: < http://www.planalto.gov.br/ccivil_03/Constituicao/Emendas/Emc_anterior1988/emc01-69.htm>. Acesso em: 22 fev 2017.

Emenda Constitucional no 14 de 12 de setembro de 1996. Disponível em: < http://www.planalto.gov.br/ccivil_03/constituicao/emendas/emc/ emc14.htm>. Acesso: 5 mar 2017.

. Emenda Constitucional no 14, de 12 de setembro de 1996. Modifica os artigos 34, 208, 211 e 212 da Constituição Federal e dá nova redação ao art.60 do Ato das Disposições Constitucionais Transitórias. Disponível em: $<$ www.planalto.gov.br>. Acesso em: 12 dez. 2009. 
. Emenda Constitucional no 19, de 4 de junho de 1998. Modifica o regime e dispõe sobre princípios e normas da Administração Pública, servidores e agentes políticos, controle de despesas e finanças públicas e custeio de atividades a cargo do Distrito Federal, e dá outras providências. Disponível em: <https://www.planalto.gov.br/ccivil_03/constituicao/emendas/emc/ emc19.htm>. Acesso em: 17 dez. 2016.

. Emenda Constitucional no 14, de 12 de setembro de 1996 (1996a). Modifica os arts. 34, 208, 211 e 212 da Constituição Federal e dá nova redação ao art. 60 do Ato das Disposições Constitucionais Transitórias. Disponível em: <https://www.planalto.gov.br/ccivil_03/constituicao/emendas/emc/emc14. htm>. Acesso em: 17 dez. 2016.

. Emenda Constitucional no 53 de 19 de dezembro de 2006. Dá nova redação dos artigos 27, 3, 30, 206, 208, 211 e 212 da Constituição Federal e ao art. 60 do Ato de Disposições Constitucionais Transitórias. Disponível em:< http://www.planalto.gov.br/ccivil_03/constituicao/emendas/emc/emc53.htm>. Acesso em: 7 mar 2017.

. Emenda Constitucional no 95 de 2016. Altera o Ato das Disposições Constitucionais Transitórias, para instituir o Novo Regime Fiscal, e dá outras providências. Disponível em: $<$ http://www2.camara.leg.br/legin/fed/emecon/2016/emendaconstitucional-95-15-dezembro-2016-784029-publicacaooriginal-151558-pl.html>. Acesso em: 11 mar 2017.

\section{. Proposta de Emenda Constitucional no 112 de 22 de setembro}

de 1999. Modifica os arts. 208, 211 e 212 da Constituição Federal e o art. 60 do Ato das Disposições Constitucionais Transitórias, criando o Fundo de Manutenção e Desenvolvimento da Educação Básica Pública e de Valorização dos Profissionais da Educação. Disponível em: <http://www.camara.gov.br/ proposicoesWeb/fichadetramitacao?idProposicao=14399>. Acesso em: 17 dez. 2016.

\section{Proposta de Emenda Constitucional no 415 de 16 de junho de}

2005. Dá nova redação ao $\S 5^{\circ}$ do art. 212 da Constituição Federal e ao art. 60 do Ato das Disposições Constitucionais Transitórias. Disponível em: <http://www.camara.gov.br/proposicoesWeb/fichadetramitacao?idProposic ao=290585>. Acesso em: 17 dez. 2016. 
. Constituição Federal de 1988. Ato de Disposições Constitucionais Transitórias. Disponível em: <https://www.planalto.gov.br/ccivil_03/constituicao/ emendas/emc/emc53.htm>. Acesso em: 21 out. 2016.

. Anteprojeto de Lei de Regulamentação do Fundo de Manutenção e Desenvolvimento da Educação Básica e de Valorização dos Profissionais da Educação: Versão Preliminar para discussão. Brasília, DF, 2004. Disponível em: <http://portal.mec.gov.br/arquivos/pdf/versaopreliminar.pdf $>$. Acesso em: 17 dez. 2016.

. Ato Adicional de 1834. Disponível em: http://www.planalto.gov.br/ ccivil_03/leis/lim/LIM16.htm. Acesso em 18 fev 2017.

. Decreto Lei no 5.239 de 23 de setembro de 1943. Dispõe sobre a cobrança e fiscalização do imposto de renda. Disponível em: <http://www. planalto.gov.br/ccivil_03/decreto-lei/Del5844.htm>. Acesso em: 20 fev 2017.

Lei no 4.024 de 20 de dezembro de 1961. Fixa as Diretrizes e Bases da Educação Nacional. Disponível em:< http://www.planalto.gov.br/ccivil_03/leis/L4024.htm>. Acesso em: 22 fev 2017.

. Lei no 9.394 de 20 de dezembro de 1996. Estabelece as Diretrizes e Bases da Educação Nacional. Disponível em: <http://www.planalto.gov.br/ ccivil_03/leis/L9394.htm>. Acesso em: 7 mar 2017.

Lei no 9.424 de dezembro de 1996. Dispõe sobre o Fundo de Manutenção e Desenvolvimento do Ensino Fundamental e de Valorização do Magistério, na forma prevista no art. 60, § 7ํㅡ, do Ato das Disposições Constitucionais Transitórias, e dá outras providências. Disponível em:<http://www. planalto.gov.br/ccivil_03/leis/L9424.htm>. Acesso em: 9 mar 2017.

. Decreto no 2.264 de 27 de junho de 1997. Regulamenta a Lei noo 9.424 de 1996. Disponível em<http://www.planalto.gov.br/ccivil_03/ decreto/d2264.htm>. Acesso em 10 mar 2017.

Lei no 11.494 de 20 de junho de 2007. Regulamenta o Fundo de Manutenção e Desenvolvimento da Educação Básica e de Valorização dos Profissionais da Educação - FUNDEB. Disponível em: <http://www.planalto.gov.br/ ccivil_03/_ato2007-2010/2007/lei/l11494.htm>. Acesso em: 8 mar 2017. 
Decreto no 6253 de 13 de novembro de 2007. Dispõe sobre o Fundo de Manutenção e Desenvolvimento da Educação Básica e de Valorização dos Profissionais da Educação - FUNDEB, regulamenta a Lei $\mathrm{n}^{0}$ 11.494, de 20 de junho de 2007, e dá outras providências. Disponível em: < http://www.planalto.gov.br/ ccivil_03/_ato2007-2010/2007/Decreto/D6253.htm>. Acesso em: 8 mar 2017.

. Ato de Disposições Constitucionais Transitórias. Disponível em: < http://www2.camara.leg.br/legin/fed/conadc/1988/constituicao.adct1988-5-outubro-1988-322234-publicacaooriginal-1-pl.html>. Acesso em: 9 mar 2017.

. Lei no 12.858 de 9 de setembro de 2013. Dispõe sobre a destinação para as áreas de educação e saúde de parcela da participação no resultado ou da compensação financeira pela exploração de petróleo e gás natural e dá outras providências. Disponível em: <https://www.planalto.gov.br/ccivil_03/_ ato2011-2014/2013/lei/l12858.htm>. Acesso em: 9 mar 2017.

CARVALHO, Laura. 10 perguntas e respostas sobre a PEC 241. Blog da Boitempo, São Paulo, 13 de outubro de 2016. Disponível em: <https:// blogdaboitempo.com.br/2016/10/13/10-perguntas-e-respostas-sobre-apec-241/>. Acesso: 12 mar. 2017.

CÂMARA DOS DEPUTADOS. Consultoria de Orçamento e Fiscalização Financeira - COFF. Análise dos efeitos da PEC no 241 sobre a Manutenção e Desenvolvimento do Ensino, 2016. Disponível: < http://www.deolhonosplanos. org.br/wp-content/uploads/2016/09/Estudo-Tecnico-11-de-2016_Analisedos-efeitos-da-PEC-241-sobre-a-MDE.pdf.>. Acesso em 11 mar 2017.

CURY, Carlos Roberto Jamil. A educação e a primeira Constituinte Republicana. In: FÁVERO, Osmar (org.). A educação nas Constituintes Brasileiras 1823-1988. 2.ed. Campinas: Autores Associados, 2001a. p. 69-80.

DE JESUS, Wellington Ferreira. A vinculação de recursos para a educação e a UDN. Cadernos de Pesquisa, v. 40, p. 213-236, 2010.

FUNDO NACIONAL DE DESENVOLVIMENTO DA EDUCAÇÃO. Matrícula, coeficientes de distribuição de recursos e receita anual prevista por Estado e Município - 2013 (com base na Portaria Interministerial no 1.496, de 
28/12/2012), 2012. Disponível em: <http://www.fnde.gov.br/financiamento/fundeb/fundeb-dados-estatisticos>. Acesso em:11 mar. 2017.

. Distribuição total do FUNDEB por Estado, 2013. Disponível em: http://www.fnde.gov.br/financiamento/fundeb/fundeb-dados-estatisticos. Acesso em: 11 mar. 2017.

GOMES, Sandra. Políticas nacionais e implementação subnacional: uma revisão da descentralização pós-Fundef. Dados, v. 52, n. 3, p. 659-690, 2009.

HORTA, José Silvério Baía. A educação no Congresso Constituinte de 1966-67. In: FÁVERO, Osmar (Org.). A educação nas Constituintes brasileiras 18231988. Campinas: Autores associados, 2001. p. 201-240.

KOLSLINSKI, Mariane Campelo. 0 processo de implementação de políticas sociais descentralizadas: o estudo do Fundef. Campinas: Ed. UNICAMP, 2000.

KANG, Thomas. Descentralização e financiamento da educação brasileira: uma análise comparativa, 1930-1964. Revista Estudos Econômicos, vol. 41, no 3, p. 573-598, 2011.

MARTINS, Paulo de Sena. 0 financiamento da Educação Básica por meio de fundos contábeis: estratégia políticas para a equidade, a autonomia e o regime de colaboração entre os entes federados. Brasília: Ed. UNB, 2009.

MENDES, Danielle Cristina Britto. FUNDEB: avanços e limites no financiamento da Educação Básica no Brasil. Revista Eletrônica de Educação, v. 6, n. 2, p. 392412, 2012.

MENEZES, J. S. S. 0 financiamento da Educação Básica pública no Brasil: 500 anos de História.. In: VII Seminário Nacional de Estudos e Pesquisas, 2006, São Paulo. Anais... Campinas: UNICAMP, 2006.

MINISTÉRIO DA EDUCAÇÃO. Nota técnica conjunta no 02, 2012. Disponível em: < http://www.fnde.gov.br/arquivos/category/54consultas?download=7658:nota-tecnica-conjunta-n-1-2012-seb-secadifnde. $>$. Acesso em: 8 mar 2017. 
MOACYR, Primitivo. A instrução e o Império. São Paulo. Companhia Editora Nacional - 1937. Disponível em: http://www.brasiliana.com.br/obras/ainstrucao-e-o-imperio2-vol. Acesso em : 22 fev. 2017.

MONLEVADE, João; FERREIRA, Eduardo. 0 Fundef e seus pecados capitais: análise do Fundo, suas implicações positivas e negativas e estratégias de superação de seus limites. Ceilândia: Idéa Editora, 1997.

MOREIRA, Jani Alves da Silva; BARROS, Fabiana Pereira. Financiamento e gestão da Educação Básica: pressupostos históricos e políticos. Revista Acta Scientiarum. Maringá, v. 37, no 4, p. 437-447, 2015.

PALMA FILHO, João Cardoso. A educação brasileira no período de 1930 a 1960: a Era Vargas. São Paulo: PROGRAD/UNESP- Santa Clara Editora, 2005.

PINTO, José Marcelino de Rezende. FINANCIAMENTO DA EDUCAÇÃO NO BRASIL: UM BALANÇO DO GOVERNO FHC (1995-2002). Revista Educação e Sociedade. Campinas, vol. 23, no 80, p. 108-135, 2002.

. Um fundinho chamado fundão. In: Dourado, L. F. (Org.). Financiamento da educação básica. Goiânia: Ed. Da UFG, 1999.

ROSSINHOLI, Marisa. Política de Financiamento da Educação Básica no Brasil: do FUNDEF ao FUNDEB. Piracicaba: UNIMEP, 2008.

SANTOS, Bruno Ricardo Viana Sadeck dos. Aspectos do federalismo brasileiro: o caso do Fundo de Manutenção e Desenvolvimento do Ensino Fundamental e Valorização do Magistério. Brasília: Ed. UND, 2006. Disponível em: <http://bdtd.ibict.br>. Acesso em: 8 mar 2017.

SAVIANI, Dermeval. 0 legado educacional no regime militar. Cad. Cedes, v. 28, n. 76, p. 291-312, 2008.

SOBREIRA, Rogério; CAMPOS, Bruno César. Investimento público em educação fundamental e qualidade de ensino: uma avaliação regional dos resultados do Fundef. Revista de Administração Pública, v. 42, n. 2, p. 327-346, 2008. 
SOUZA, Maria Inês Salgado de. Os empresários e a educação: o IPES e a política educacional após 1964. Petrópolis: Vozes, 1981.

TEIXEIRA, Anísio. Sôbre o problema de como financiar a educação do povo brasileiro. Revista Brasileira de Estudos Pedagógicos, v. 80, n. 194, p. 102113, 1999.

VAZQUEZ, Daniel Arias. Educação, descentralização e desequilíbrios regionais: os impactos do Fundef. Campinas: Ed. UNICAMP, 2003. Disponível em: <http://bdtd.ibict.br>. Acesso em: 6 mar 2017.

VASCONCELOS, Dimas Augusto. Custeio da Educação Pública na Era Vargas: A caixa escolar do Ceará (1930-1945). Fortaleza: UFC, 2013.

WERLE, Flávia Obino Corrêa. Obrigatoriedade e gratuidade da instrução elementar: articulação entre o público e o privado. Revista de Administração Educacional. Recife, v.1, n.1, jul./dez, p. 09-26, 1997.

Artigo recebido em: 15-9-2017

Aprovado em: 27-11-2018

\section{Maria Stela Campos da Silva}

Doutora em Direito pela Universidade Federal do Pará (UFPA); mestre em Direito pela Universidade Federal de Pernambuco (UFPE); professora do Programa de Pós-Graduação em Direito da UFPA; advogada. E-mail: stelacampos@gmail.com

\section{Bianca Araujo de Oliveira Pereira}

Mestre em Direito pela Universidade Federal do Pará (UFPA); professora substituta da Faculdade de Etnodiversidade da UFPA; advogada. E-mail: bianca_ araujo19@hotmail.com

Universidade Federal do Pará. Instituto de Ciências Jurídicas | Programa de Pós-Graduação em Direito. Rua Augusto Corrêa, 01. Campus Universitário do Guamá. Belém, Pará, Brasil - CEP 66.075.110 